\title{
PARAMETER PREDICTION OF HYDRAULIC FRACTURE FOR TIGHT RESERVOIR BASED ON MICRO-SEISMIC AND HISTORY MATCHING
}

\author{
KAI ZHANG $,{ }^{*}, \ddagger$ XIAOPENG MA,${ }^{*}$ YANLAI LI, ${ }^{\dagger}$ HAIYANG WU, \\ CHENYU CUI, ${ }^{*}$ XIAOMING ZHANG ${ }^{*}$ HAO ZHANG* and JUN YAO* \\ ${ }^{*}$ China University of Petroleum (East China) \\ Qingdao, Shandong 266580, P. R. China \\ ${ }^{\dagger}$ CNOOC LTD, Tianjin 300452, P. R. China \\ ${ }_{\ddagger}$ zhangkai@upc.edu.cn
}

Received December 6, 2017

Accepted January 5, 2018

Published March 7, 2018

\begin{abstract}
Hydraulic fracturing is an important measure for the development of tight reservoirs. In order to describe the distribution of hydraulic fractures, micro-seismic diagnostic was introduced into petroleum fields. Micro-seismic events may reveal important information about static characteristics of hydraulic fracturing. However, this method is limited to reflect the distribution area of the hydraulic fractures and fails to provide specific parameters. Therefore, micro-seismic technology is integrated with history matching to predict the hydraulic fracture parameters in this paper. Micro-seismic source location is used to describe the basic shape of hydraulic fractures. After that, secondary modeling is considered to calibrate the parameters information of hydraulic fractures by using DFM (discrete fracture model) and history matching method. In consideration of fractal feature of hydraulic fracture, fractal fracture network model is
\end{abstract}

This is an Open Access article published by World Scientific Publishing Company. It is distributed under the terms of the Creative Commons Attribution 4.0 (CC-BY) License. Further distribution of this work is permitted, provided the original work is properly cited. 
established to evaluate this method in numerical experiment. The results clearly show the effectiveness of the proposed approach to estimate the parameters of hydraulic fractures.

Keywords: Micro-Seismic Source Location; History Matching; Fractal Fracture Network; Secondary Modeling; Parameter Prediction of Hydraulic Fractures; Discrete Fracture Model.

\section{INTRODUCTION}

The fracture is the high permeability channel and fluid in the reservoir flows into fracture priorly! ${ }^{1]}$ So understanding of hydraulic fracture information is a crucial work for development of low permeability reservoirs. There are many common monitoring measures for description of artificial fractures, such as logging test, particle tracing, micro-seismic monitoring, etc. Specially, micro-seismic monitoring is one of the most popular methods. ${ }^{2}$

Micro-seismic interpretation may predict the general area of fractures ${ }^{3}$ However, it cannot give a definitive answer to how the hydraulic fractures distribute and whether it reclose after fracturing, let alone whether the fractures can establish flow connection. Therefore, we integrated micro-seismic interpretation results with history matching to predict hydraulic fracture parameters. The purpose of this work is to clearly recognize the tight reservoirs fracturing effect and the perforating direction of fractured wells.

In micro-seismic interpretation theory, the source location is the core aspect and it is the foundation of the inversion of hydraulic fracture. The goal of source location is to calculate the minimum propagation path of seismic wave arriving each receiving position. According to Fermat theory or Snell's law, seismic wave traveled along the shortest propagation path, like the shooting ray tracing method, which is based on Snell's law ${ }^{4 / 5}$ Several typical methods are mainly divided into two categories: local ray tracing method $\frac{10}{10}$ and global ray tracing theory $11-14$ In terms of source location model, the classic method is time difference method. This method was first proposed by Geiger in 1912, the least squares objective function is used to locate the target ${ }^{15}$ Later, Waldhauser used two events' simulation results to establish the double difference objective function for position constraint 16

In terms of optimization methods, many experts and scholars have done a lot of studies, there are two major categories: local optimization method and global optimization method. Local optimization method mainly contains classical gradient methods ${ }^{\frac{17}{17}}$ while global optimization method includes the grid-search algorithm, 18 genetic algorithm, 19 simulated annealing and particle swarm optimization, 20 etc. In order to improve the location accuracy, Sato and Skoko first attempted to test the single source ground observations of 12 different geophone arrangement by Monte Carlo method, which summed up the best geophone monitoring placement ${ }^{21}$ Kijko first proposed the general theory of optimum geophone position, $\frac{22}{22}$ and Song et al. proposed micro-seismic source vector inversion method which improved the inversion accuracy 23

Discrete Fracture Model (DFM) is one of the most popular methods so far. The DFM was first proposed in early 1990s.24,25] Izadi and Yildiz simulated the transient flow of the fractured porous medium to study the effect of discrete fracture for wellbore pressure drop and infinite homogeneous reservoir pressure. ${ }^{26}$ In the same year, Tae and David introduced fractal theory and used fractal discrete fracture network model to estimate the reservoir porosity 27 Moinfar compared two types of DFM and dual-medium models which illustrate the significant advantages of the DFM in solving the local strong heterogeneity medium and large fractures. ${ }^{28}$ Lacazette et al. studied the principle of the extension of hydraulic fractures, they also simulated the geometric shape and distribution by means of discrete fracture network model. $\stackrel{29}{ }$ In 2012, Sandve et al. developed a discrete fracture model for simulating the flow behavior of DFM based on the Matlab Reservoir Simulation Toolbox (MRST)!30[31 In this paper, the DFM is used to simulate production of reservoir with different fracture parameters.

Simultaneous Perturbation Stochastic Approximation (SPSA) is an effective gradient approximation algorithm. An early paper on the subject is given by Spall ${ }^{32}$ and the foundational paper providing the key theory and justification is given by Spall. ${ }^{33}$ It is applied for optimizing systems with 
multiple unknown parameters. The search direction is obtained by simultaneously perturbing control variables. So it avoids calculating the true gradient of the problem. In this paper, we use SPSA algorithm to match the dynamic data of oil field and optimize the micro-seismic source location.

The reservoirs properties have fractal characteristic 34 During fracturing process, induced fractures are opened on the side of main fracture and hydraulic fracture which connect nature fracture to form complex network. Some researchers suggest that fracture network has fractal and bifurcate feathers and introduce stimulated fractal tree method to characterize the hydraulic fracture network $[38] 40]$ In this paper, the single fracture model and the fractal fracture network model are used to evaluate this method.

\section{MICRO-SEISMIC INTERPRETATION}

\subsection{Forward Modeling Based on Shooting Ray Tracing Method}

For the low-porosity and low-permeability characteristics of tight reservoirs, the similar properties of the formation are classified to simplify the geologic model as the horizontal layered homogeneous formation. It includes the following steps:

(1) Assume that $M$-layer homogeneous medium and the distance from the layer interface to the ground are Layer $\_h=\left[\right.$ Layer $\_h_{1}$ Layer $\_h_{2} \ldots$ Layer_ $\left.h_{M}\right]$. The propagation velocity of $\mathrm{P}$-wave in each layer is Layer $\_v=\left[\right.$ Layer_$\_v_{1}$ Layer $\_v_{2} \ldots$ Layer_ $\left.v_{M}\right]$.

(2) Set $N$ geophones and the initial propagation angle $\theta_{i 1}$. As shown in Fig 1, the intersection point $\left(x_{j}, y_{j}, z_{j}\right)$ is calculated based on Snell's law, then obtain the propagation angle together

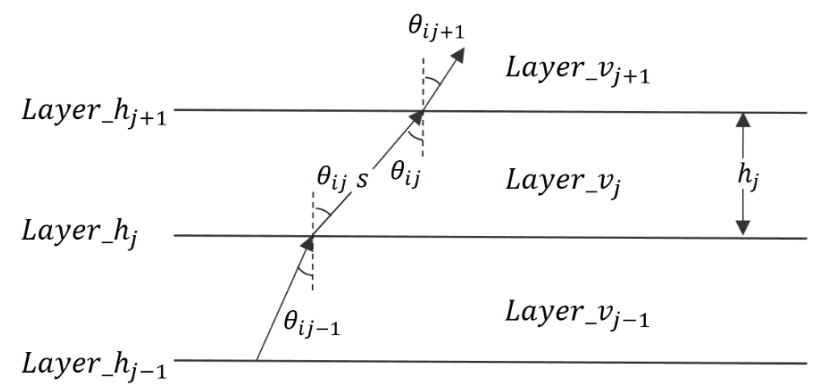

Fig. 1 Schematic representation of shooting ray tracing based on Snell's law. with propagation path and travel-time of seismic waves, which can be calculated as follows:

$$
\begin{aligned}
\frac{\sin \theta_{i 1}}{\text { Layer_} \__{1}}= & \frac{\sin \theta_{i 2}}{\text { Layer_v } v_{2}}=\cdots=\frac{\sin \theta_{i M}}{\text { Layer_} \_v_{M}}, \\
s_{i}= & \sum_{j=1}^{n_{i}} h_{i j} \cos \left(\theta_{i j}\right), \\
& i=1,2, \ldots, N ; n_{i}=1,2, \ldots, M, \\
T_{\text {obs }}^{i}= & \sum_{j=1}^{n_{i}} h_{i j} \cos \left(\theta_{i j}\right) / \text { Layer_v } v_{j}, \\
& i=1,2, \ldots, N ; n_{i}=1,2, \ldots, M,
\end{aligned}
$$

where $s_{i}$ denotes the propagation path of seismic waves from the micro-seismic source location to the $i$ th geophone, $n_{i}$ represents the geophone number, $h_{i j}$ shows the projection of ray in the longitudinal height, $\theta_{i j}$ indicates the propagation angle at the $j$ th layer of seismic waves in the process of arriving the $i$ th geophone, Layer $\_v_{j}$ is the velocity of seismic waves in the $j$ th layer, $T_{\text {obs }}^{i}$ denotes the travel-time of seismic waves from the source arriving the $i$ th geophone.

(3) When ray tracing is performed using the improved shooting method, set the initial emission angle of micro-seismic event. The dichotomy method is used to adjust the ray emission angle.

(4) Output the ray path (Fig. 2).

\subsection{Objective Function}

Travel-time differences of adjacent detector are used to construct the objective function. This method not only avoids the complication of inversion earthquake time but also reduces the disturbance of the seismic wave propagating in the formation, which enhances the anti-noise ability. Here is a brief description of objective function.

Set $N$ geophones in the formation, where $\left(x_{\text {true }}\right.$, $\left.y_{\text {true }}, z_{\text {true }}\right)$ denotes the source location and $t_{\text {obs }}^{i}$ represents the real observation time of seismic waves from the source location to the $i$ th geophone. Here, $t_{\text {obs }}^{i}$ is composed of earthquake time and travel-time, by which $t_{\mathrm{obs}}^{i}=t_{0}+T_{\mathrm{obs}}^{i}$. In order to eliminate the influence of inversion earthquake time, we could write the first arrival time difference of two adjacent 


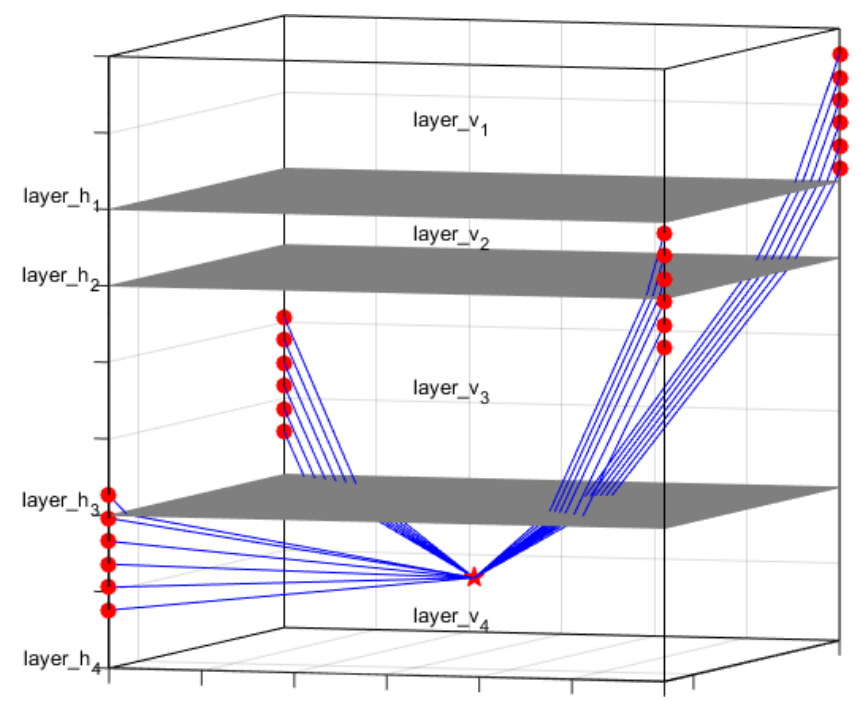

Fig. 2 Schematic of micro-seismic forward modeling based on shooting ray tracing. Blue line shows the ray tracing path of seismic waves in 3D layered homogeneous formation, • represents the location of geophones, $\star$ represents the microseismic source position.

geophones as follows:

$$
\begin{aligned}
\Delta t_{\mathrm{obs}}^{i} & =t_{\mathrm{obs}}^{i+1}-t_{\mathrm{obs}}^{i} \\
& =\left(t_{0}+T_{\mathrm{obs}}^{i+1}\right)-\left(t_{0}+T_{\mathrm{obs}}^{i}\right) \\
& =T_{\mathrm{obs}}^{i+1}-T_{\mathrm{obs}}^{i}, \quad i=1,2, \ldots, N-1 .
\end{aligned}
$$

As shown in Eq. (4), the first arrival time difference of two adjacent geophones is the travel-time difference of the seismic wave. Therefore, it can be defined as follows:

$$
\Delta T_{\mathrm{obs}}^{i}=T_{\mathrm{obs}}^{i+1}-T_{\mathrm{obs}}^{i}, \quad i=1,2, \ldots, N-1 .
$$

Set $\left(x_{0}, y_{0}, z_{0}\right)$ as initial search point in solving region, according to Sec. 2.1, the shooting ray tracing method is used to calculate the travel-time of seismic wave arriving each geophone, then calculate the travel-time difference of two adjacent geophones:

$$
\Delta T_{\text {cal }}^{i}=T_{\text {cal }}^{i+1}-T_{\text {cal }}^{i}, \quad i=1,2, \ldots, N-1 .
$$

Therefore, we can establish the relationship between the observation and calculation data, and then get the objective function based on doubledifference method:

$$
f=\left\|\Delta T_{\text {cal }}-\Delta T_{\text {obs }}\right\|=\sum_{i=1}^{N-1}\left|\Delta T_{\text {cal }}^{i}-\Delta T_{\text {obs }}^{i}\right| .
$$

After establishing the objective function, the following is to minimize the objective function and get the optimal point $\left(x_{\text {best }}, y_{\text {best }}, z_{\text {best }}\right)$, which is the inversed source location.

\section{PARAMETER PREDICTION OF HYDRAULIC FRACTURE BASED ON DYNAMIC DATA}

\subsection{Discrete Fracture Model}

Many experts and scholars have been giving much research in this aspect $14-44$ and they suggest that DFM can accurately simulate reservoir production. DFM was first studied in Rock Mechanics, it holds that the matrix and the fractures are inter-connected each other, and fluid flows both in the matrix and the fractures. DFM can effectively reduce the computational complexity without influencing the accuracy of calculation. Moreover, DFM could give better description of the heterogeneity and seepage characteristics of the fractures. Therefore, combined with the initial shape of the hydraulic fracture that deduced by micro-seismic data, the Discrete Fracture Model can be used to reflect the shape and distribution of the fracture in the flow model.

After building the mesh model and defining injection/production wells in the region, and with the help of MATLAB Reservoir Simulation Toolbox (MRST) to simulate the real reservoir production, we can obtained the oil/water production, total oil/water production and other dynamic production information, that is the following inversion index.

\subsection{Fractal Network}

During fracturing process, induced fractures are opened on the side of main fracture and hydraulic fracture which connect nature fracture to form complex network. ${ }^{45}$ Discrete fracture network model (DFN) was proposed to characterize fracture network early $46 / 47$ Fracture network is depicted as orthogonal and regular (Fig. 3) in DFN. But in practice fracture network has fractal and bifurcate feathers. This is similar to tree branch growth. For this reason, some researchers introduce simulated fractal tree method to describe fracture network more realistically.

Lindenmayer proposed the L-system theory based on fractal theory to depict plant growth. $\frac{48}{6}$ L-system is widely used to simulate plant growth and the basic idea of L-system is the substitution of strings. The substitution rule complied with Fibonacci Sequence, that is $G(n)=G(n-1)+$ $G(n-2)$. For example, a string substitution is shown as: $b \rightarrow a \rightarrow a b \rightarrow a b a \rightarrow a b a a b \rightarrow \cdots$. The steps 


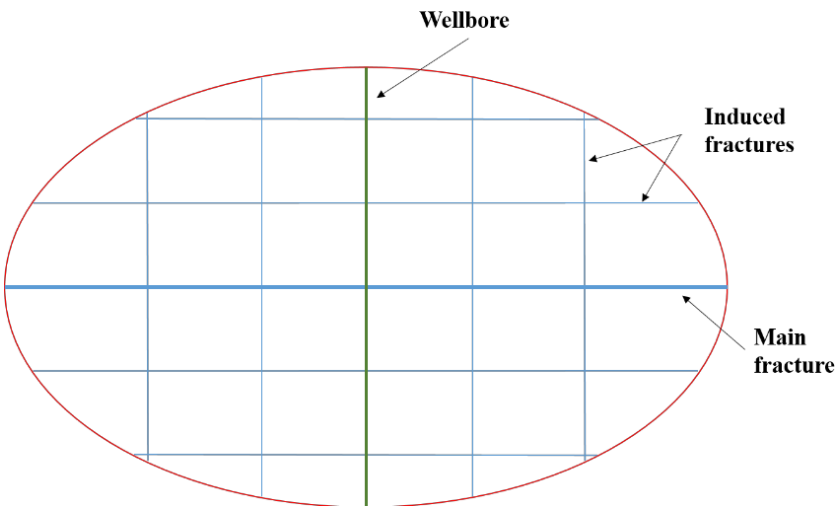

Fig. 3 Schematic of DFN model.

of creating fractal tree are listed below:

(1) Specify the strings sequence.

(2) Specify the initial point, intersection angle $\delta$, iteration step length $L$ and iteration times, etc.

(3) Define the rule of each string in sequence.

(4) Iterate the strings sequence according to rules.

Random mechanism is added to depict tree growth more realistically. The simulated fractal tree is shown in Fig. 4 by following L-system rules. As the number of iterations increase, the shape of the tree becomes more complex.
Rule 1: $F F-[-F+F+F]+[+F-F-F]$ random range $0.7-1$.

Rule 2: $F F+[+F+F]-[+F]$ random range 0.350.7 .

Rule 3: $F[+F] F[-F[+F]]$ random range $0-0.35$.

$F=$ Move forward a step of length $L$

$+=$ Turn right by angle $\delta$

$-=$ Turn left by angle $\delta$

$[=$ Push the current state onto a pushdown stack

] = Pop a state from the stack and make it the current state.

The complex fracture network is regarded as the system of main fracture and induced fracture with fractal characteristics. Therefore, the simulated tree growth method is used to characterize the fracture network. For saving the computation costs, the random mechanism is not considered in this paper. The fracture network shape in different iterations is shown in Fig. 5 .

Considering the fractal dimension of practical fracture network, $\frac{49}{4}$ the L-system rule is iterated twice to approximate the morphology of practical fracture.

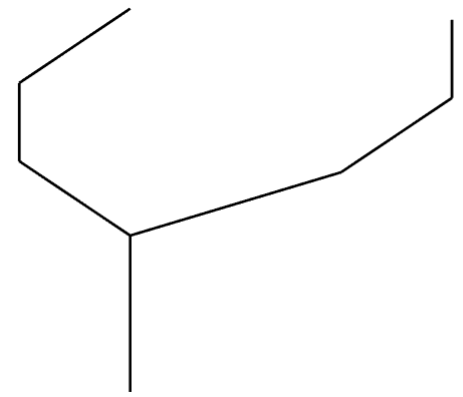

Iteration 1 times

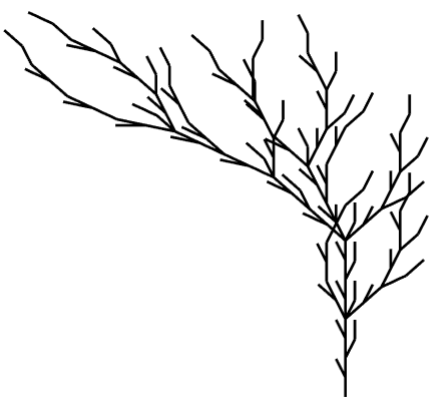

Iteration 3 times

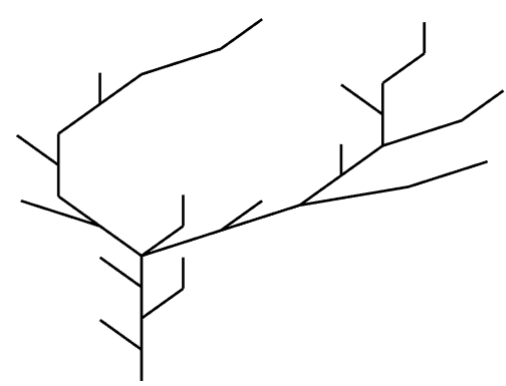

Iteration 2 times

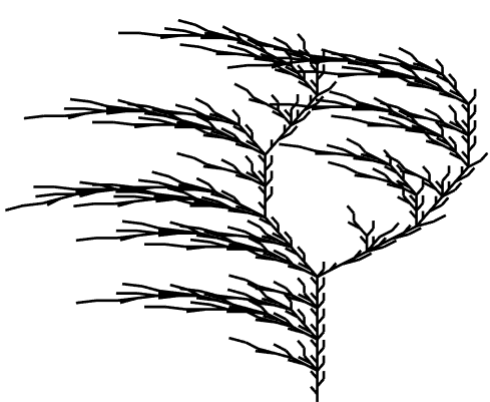

Iteration 4 times

Fig. 4 Schematic of fractal tree. 

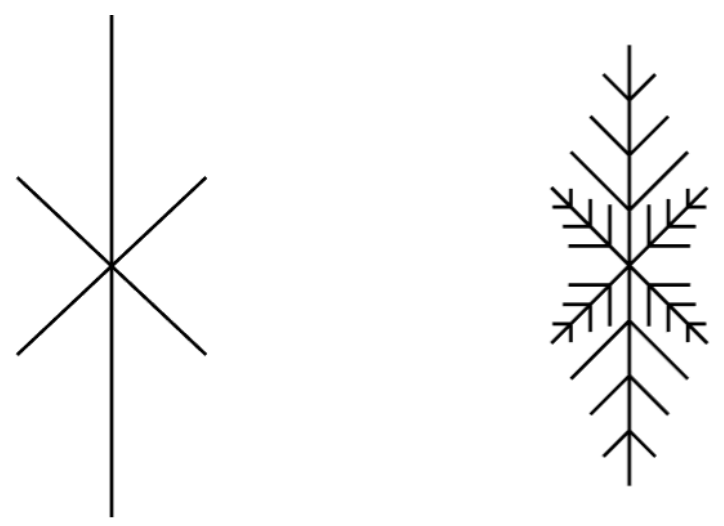

(a)

(b)

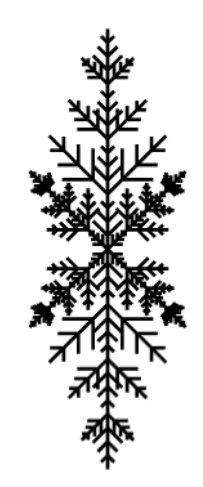

(c)

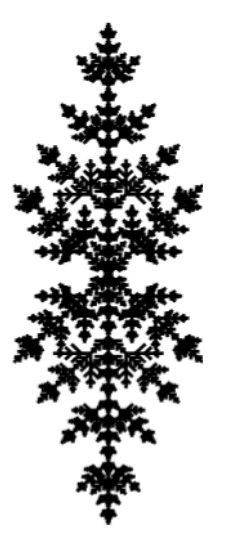

(d)

Fig. 5 Schematic of fractal fracture.

\subsection{Bayesian Model Prediction and Solution}

The Bayesian theory can give probability estimation function of fracture distribution on the basis of the real production and pressure data of reservoir injection/production well. If the probability estimation reaches the minimum value, the fracture distribution will approximate to the maximum probability of the real shape. Since the Bayesian theory is a method of the probability statistics, we need to generate prior model first, then give the probability density function of the hydraulic fracture distribution. Based on the micro-seismic data obtained from the rough distribution of the hydraulic fractures, and use it to construct the prior model, the static information of the fracture distribution will be contained. Therefore, based on Bayesian theory, construct the mathematical model that contains static geological data and dynamic production data, which can inverse the shape of the hydraulic fracture more accurately.

Optimization model is aimed at obtaining the maximum of Bayesian probability density function. In the solving process, the constraint optimization is carried out by means of logarithmic transformation and penalty function.

Objective function:

$$
\begin{aligned}
f(m)= & \frac{1}{2}\left(m-m_{p r}\right)^{T} C_{M}^{-1}\left(m-m_{p r}\right) \\
& +\frac{1}{2}\left(d_{\mathrm{obs}}-g(m)\right)^{T} C_{D}^{-1}\left(d_{\mathrm{obs}}-g(m)\right),
\end{aligned}
$$

where $m$ denotes the parameters of the hydraulic fracture, like half-length and azimuth angle and $m_{\mathrm{pr}}$ denotes the prior estimation of the reservoir model. $C_{M}$ represents the covariance matrix of the mean value $m_{\text {pr }}$ generated by the geo-statistics method on the basis of the prior information. $d_{\mathrm{obs}}$ is the real observation data, like oil/water production. $g(m)$ denotes the calculated data generated by reservoir simulator. $C_{D}$ denotes the covariance matrix composed by measurement error of observation data.

\subsection{SPSA Algorithm Implementation}

SPSA algorithm was first modified by Spall ${ }^{32}$ based on the Kiefer-Wolfowitz stochastic approximation algorithm (K-W algorithm), and Spal ${ }^{33}$ carefully tested this algorithm. Since then, many experts and scholars have carried on the inheritance and development of it. 50151

The following steps are described in more detail:

(1) Initialize variables and coefficients selection: Set initial position of micro-seismic events randomly $X_{0}=\left(x_{0}, y_{0}, z_{0}\right)$, then perturbate the $X_{0}$ to get new parameter variable $X_{0}^{\prime}$

$$
X_{0}^{\prime}=X_{0}+\alpha \cdot \Delta X,
$$

where $\alpha$ is the disturbance step, and $\Delta X$ is the disturbance vector and it is generated randomly. Then calculate the objective function values are $F\left(X_{0}\right)$ and $F\left(X_{0}^{\prime}\right)$.

(2) Using the difference of the two function values to get a random gradient value

$$
G\left(X_{0}\right)=\frac{F\left(X_{0}^{\prime}\right)-F\left(X_{0}\right)}{\alpha \cdot \Delta X} .
$$

(3) The random gradient of SPSA is obtained by

$$
G\left(X_{0}\right)=\frac{F\left(X_{0}+\alpha \cdot \Delta X\right)-F\left(X_{0}\right)}{\alpha} \cdot \Delta X .
$$


(4) Update the $X_{0}$.

$$
X_{\text {update }}=X_{0}+\alpha \cdot G\left(X_{0}\right) .
$$

Then the updated function value is calculated by

$$
F\left(X_{\text {update }}\right)=F\left(X_{0}+\alpha \cdot G\left(X_{0}\right)\right) .
$$

(5) If the iteration value is satisfied or arrives the maximum iterations number, then stop the program and output the optimal solution.

The above method is the process of SPSA algorithm. The "approximate gradient" is solved to modify the search direction, which is to close the minimum.

\section{NUMERICAL EXPERIMENT}

\subsection{Reservoir Model}

We consider a four-layer homogeneous formation, and the fourth layer is the tight reservoir of size $600 \times 600 \times 50 \mathrm{~m}$. The depth of each layer interfaces is Layer_ $h=\left[\begin{array}{ll}2100 & 2150 \\ 2300 & 2350\end{array}\right] \mathrm{m}$, and the velocities of $\mathrm{P}$-wave in every layers are Layer_ $v=$ [1600 200024002800$] \mathrm{m} / \mathrm{s}$, respectively.

Set 13 wells in the reservoir, four injection wells and nine production wells, in the initial state the reservoir is fully saturated with oil. It is assumed that the reservoir is homogeneous and the hydraulic fractures penetrate the entire reservoir. Therefore, the reservoir can be simplified as 2D plane, well placement is shown in Fig. 6. Fracturing occurs in the position of Inj2, Inj4 and Pro9.

Based on the previous model, the 3D geological model is simplified to $2 \mathrm{D}$ plane. Set up the tight reservoir model, as shown in Table 1.

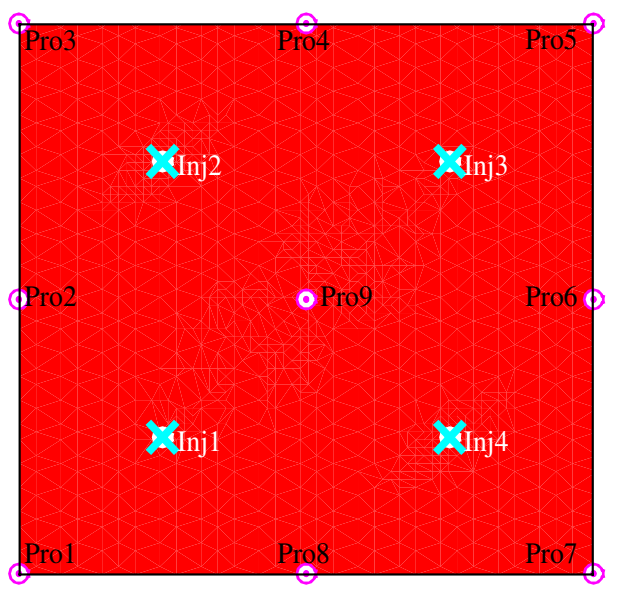

Fig. 6 Well location distribution.
Table 1 Parameters of Reservoir Model, Homogeneous Example.

\begin{tabular}{ll}
\hline Parameter & Test Case \\
\hline Phase & Two-phase (oil/water) \\
Simulate time & 365 days \\
Reservoir dimensions & $600 \times 600 \mathrm{~m}$ \\
Injection well constraint & Water rate $\left(4 \times 25 \mathrm{~m}^{3} / \mathrm{d}\right)$ \\
Reservoir porosity & 0.01 \\
Reservoir permeability & $1 \mathrm{mD}$ \\
Fracture porosity & 0.5 \\
Fracture permeability & $12000 \mathrm{D}$ \\
\hline
\end{tabular}

\subsection{Micro-Seismic Inversion}

The position of geophones is shown in Table 2 .

As shown in Table 2 the first geophone depth is $-2017 \mathrm{~m}$ and the 24 th geophone depth is $-2316 \mathrm{~m}$, adjacent two geophones height difference is $13 \mathrm{~m}$.

The travel time obtained by forward model is added to the random noise, which obeys $N(0$, $\left.0.00025^{2}\right)$, and it represents the first arrival detecting error. The new synthetic data will be used as observation data to perform the following inversion study.

The fracturing process was designed with 2000 micro-seismic events, the Inj2 and Inj4 generated 600 events respectively, and Pro9 generated 1000 events. Results of the micro-seismic inversion are shown in Figs. 7 and 8.

From Fig. 17, it can be concluded that the inversion result is satisfied, and the distribution of inversion micro-seismic events is consistent with the real situation. Moreover, in conjunction with Fig. 8, density distribution map shows that the inversion results is more accurate and the distribution of the point cloud also can be described.

In Table 3, the maximum deviation error in the $X$-direction is $25.4367 \mathrm{~m}$, the best control is within $10 \mathrm{~m}$. The error in the $Y$-direction is relatively small, most of the error is less than $15 \mathrm{~m}$, and the average error is less than $1.5 \mathrm{~m}$. In the direction of $Z$-axis, the error is within $20 \mathrm{~m}$ mostly.

\subsection{Single Fracture Case}

Hydraulic fracture is different from natural fracture, the fracturing point is fixed, and the fracture must be through the fracturing point. For saving computational cost, two parameters used in the optimization process, that is, orientation and half-length.

Synthetic micro-seismic events and the real hydraulic fracture are generated, as shown in Fig. 9. 
Table 2 Position of Geophones.

\begin{tabular}{lllllllllllll}
\hline Number & $\mathbf{1}$ & $\mathbf{2}$ & $\mathbf{3}$ & $\mathbf{4}$ & $\mathbf{5}$ & $\mathbf{6}$ & $\mathbf{7}$ & $\mathbf{8}$ & $\mathbf{9}$ & $\mathbf{1 0}$ & $\mathbf{1 1}$ & $\mathbf{1 2}$ \\
\hline$X$ & 0 & 0 & 0 & 0 & 0 & 0 & 0 & 0 & 0 & 0 & 0 & 0 \\
$Y$ & 0 & 0 & 0 & 0 & 0 & 0 & 600 & 600 & 600 & 600 & 600 & 600 \\
$Z$ & 2017 & 2030 & 2043 & 2056 & 2069 & 2082 & 2095 & 2108 & 2121 & 2134 & 2147 & 2160 \\
\hline Number & $\mathbf{1 3}$ & $\mathbf{1 4}$ & $\mathbf{1 5}$ & $\mathbf{1 6}$ & $\mathbf{1 7}$ & $\mathbf{1 8}$ & $\mathbf{1 9}$ & $\mathbf{2 0}$ & $\mathbf{2 1}$ & $\mathbf{2 2}$ & $\mathbf{2 3}$ & $\mathbf{2 4}$ \\
\hline$X$ & 600 & 600 & 600 & 600 & 600 & 600 & 600 & 600 & 600 & 600 & 600 & 600 \\
$Y$ & 0 & 0 & 0 & 0 & 0 & 0 & 600 & 600 & 600 & 600 & 600 & 600 \\
$Z$ & 2173 & 2186 & 2199 & 2212 & 2225 & 2238 & 2251 & 2264 & 2277 & 2290 & 2303 & 2316 \\
\hline
\end{tabular}

Ttue Micro-seismic Event

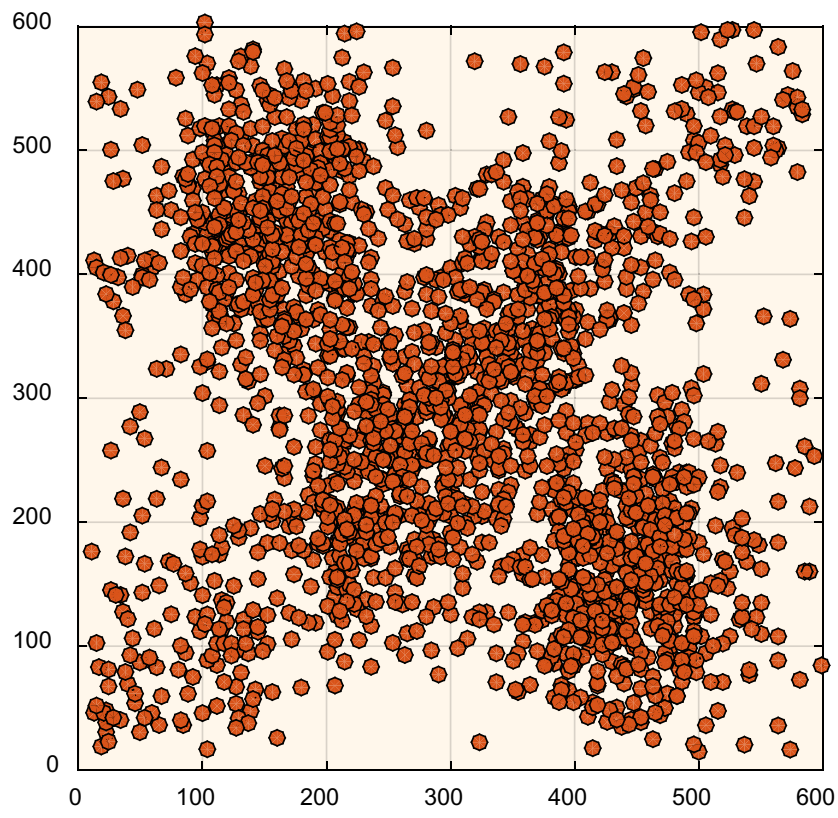

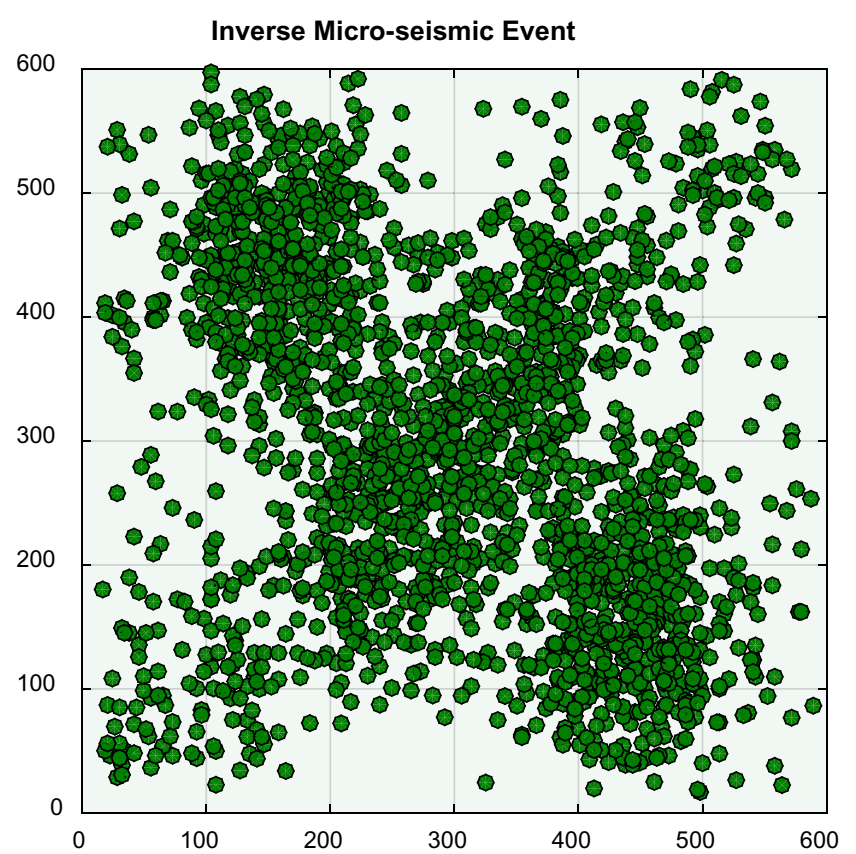

Fig. 7 The true micro-seismic events (left) and the inversed micro-seismic location (right).

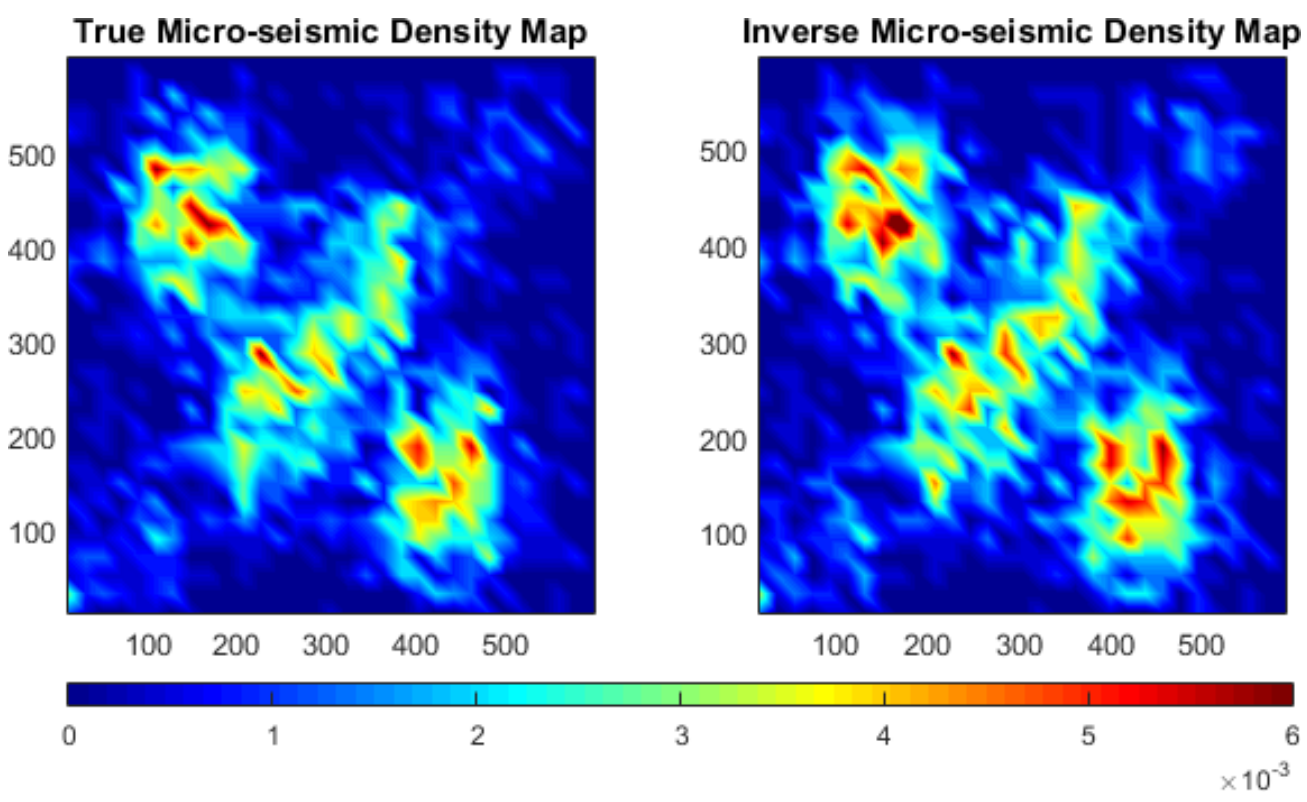

Fig. 8 Density distribution map of the true micro-seismic events and the inversion points. 
Table 3 The Absolute Error Analysis.

\begin{tabular}{lccr}
\hline Absolute Error & \multicolumn{3}{c}{ Axis } \\
\cline { 2 - 4 } & \multicolumn{1}{c}{$\boldsymbol{X}$} & $\boldsymbol{Y}$ & $\boldsymbol{Z}$ \\
\hline Maximum/m & 25.4367 & 15.5575 & 44.9259 \\
Minimum/m & $7.3148 \mathrm{e}-04$ & $7.3030 \mathrm{e}-4$ & 0.0070 \\
Average/m & 4.2225 & 1.5100 & 7.4160 \\
\hline
\end{tabular}

As shown in Fig. 9, micro-seismic events are mainly distributed in ellipse enclosed area, the green dots denote the micro-seismic events and the blue dots denote the inversion micro-seismic events. The black lines denote the fractures. According to the range of inversion micro-seismic event distribution, fitting the fracture on the concentrated area of the point cloud (Fig. 8), then the half-length and azimuth angle of hydraulic fractures are assumed.

Parameter information of speculated fracture obtained from the micro-seismic data interpretation, which is regarded as the initial fracture model for the next analysis, as shown in Table 4 .

Table 4 indicates that the hydraulic fracture includes four parameters, where the fracturing point $\left(x_{0}, y_{0}\right)$ is fixed. Because fracture is inevitable through $\left(x_{0}, y_{0}\right)$, we needn't optimize it in the process of parameter matching. But we need it to calculate the two endpoints of the fracture, as given in Table 4 .

The history matching is implied to estimate the fracture parameters further based on initial fracture shape. The production data of final model are compared with the real fracture model in Figs. 10 13, which shows the result of several wells.

It can be seen from Figs. 10 13, that both water production and oil production are able to match basically, where Pro2, Pro8 and Pro9 are matched better. Water production data of Pro1 matched better than oil production because the second final fracture is longer than the real one so that the water production is much higher.

The parameters of real fracture model and final fracture are compared in Table 5

Based on the DFM, the fractures distribution and the remaining oil saturation distribution are shown in Figs. 14, 16,

It can be seen clearly from Figs. 15 and 16 that the longer fracture in the middle matched best, and for the other two fractures, either azimuth or halflength had a better correction compared with initial model. In combination with the specific parameters in Table 5 , the matching results are more obvious. Therefore, the method used in this paper can accurately predict the effective form of hydraulic fractures.

\subsection{Fractal Fracture Network Case}

In this section, we suppose the hydraulic fracture network symmetrical distribution on both sides of well. On the basis of fractal theory, the real fracture network model and initial fracture model are established, as shown in Fig. 17.
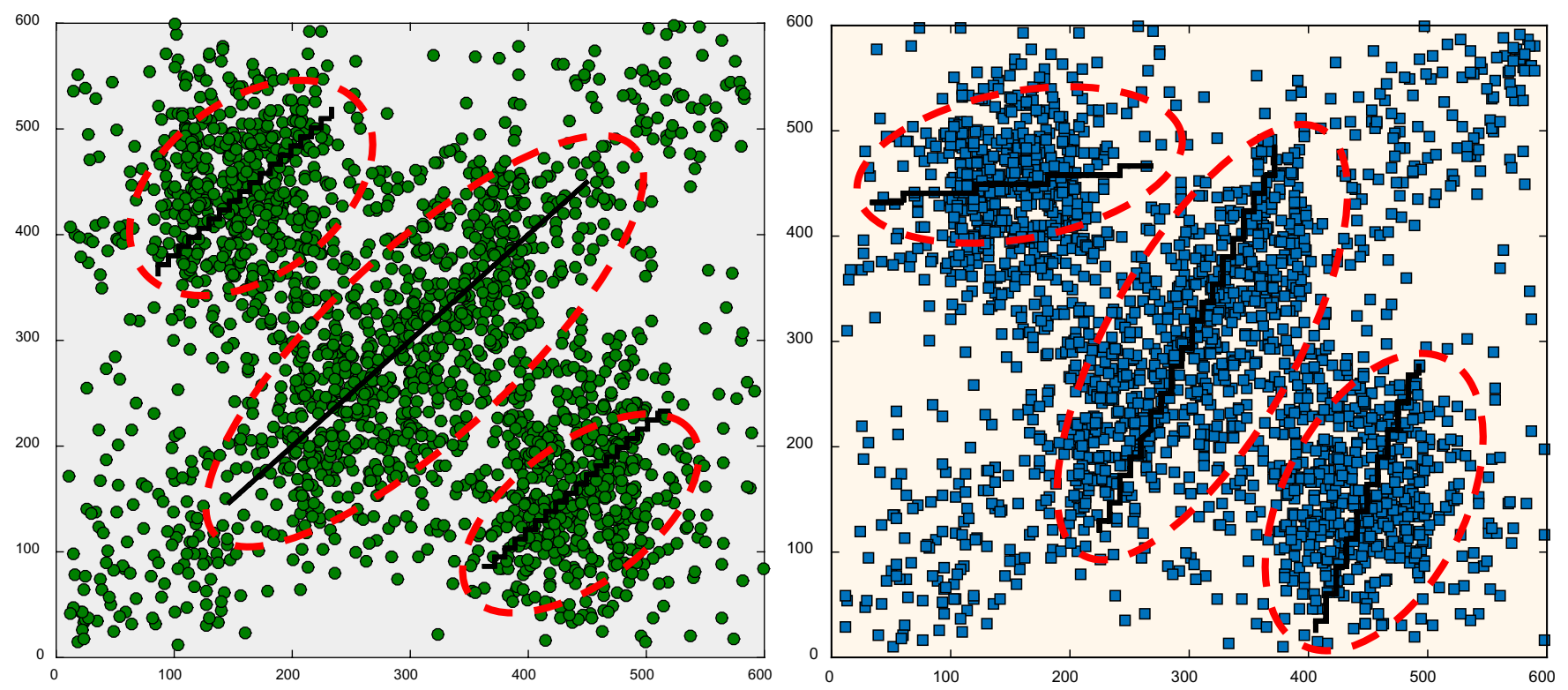

Fig. 9 The distribution of real fracture (left) and initial fracture (right). 
Table 4 Initial Parameters.

\begin{tabular}{ccccc}
\hline $\begin{array}{c}\text { Parameters/ } \\
\text { Number }\end{array}$ & $\boldsymbol{x}_{\mathbf{0}}$ & $\boldsymbol{y}_{\mathbf{0}}$ & $\boldsymbol{\alpha}$ & $\boldsymbol{L}$ \\
\hline 1 & 300 & 300 & 67.47 & 394.03 \\
2 & 150 & 450 & 10 & 240 \\
3 & 450 & 150 & 70 & 260 \\
\hline
\end{tabular}

From Fig. 8 the general micro-seismic events concentrated area can be estimated. The initial fracture network shape can be estimated according to the distribution of inversed micro-seismic events (Fig. [17).

The reservoir model parameters is listed in Table6. History matching method is used to predict
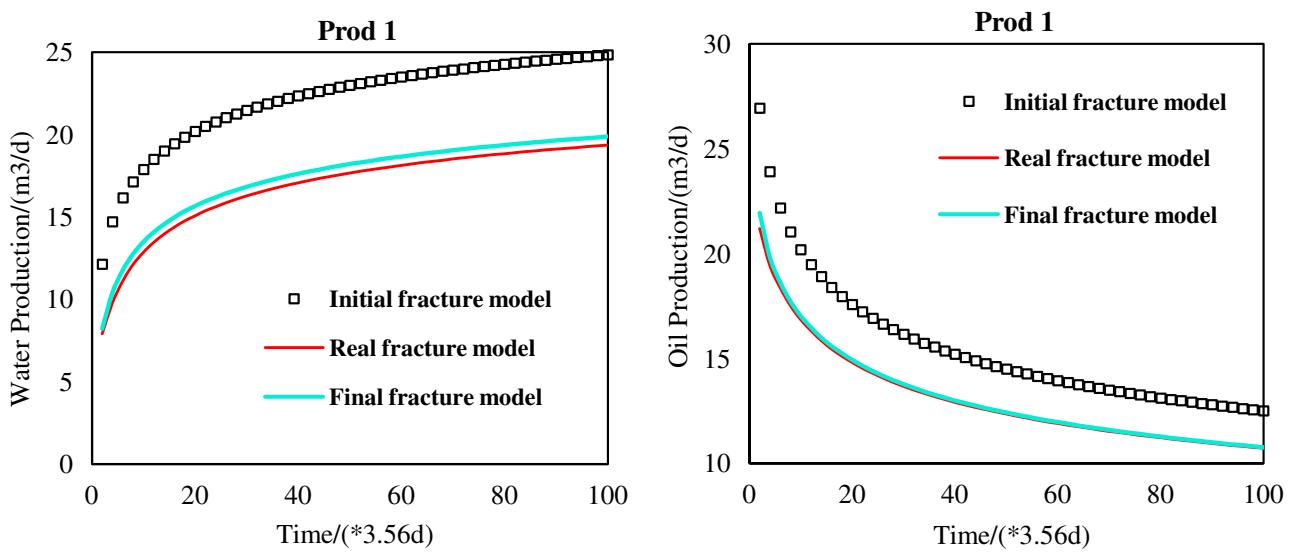

Fig. 10 Production data of Pro1.
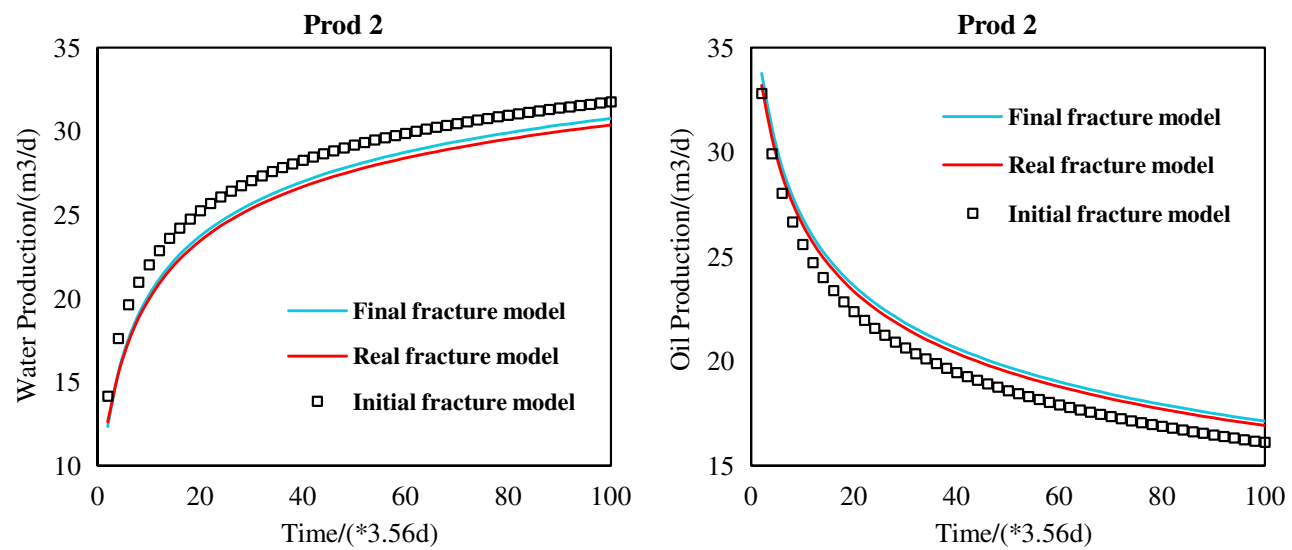

Fig. 11 Production data of Pro2.
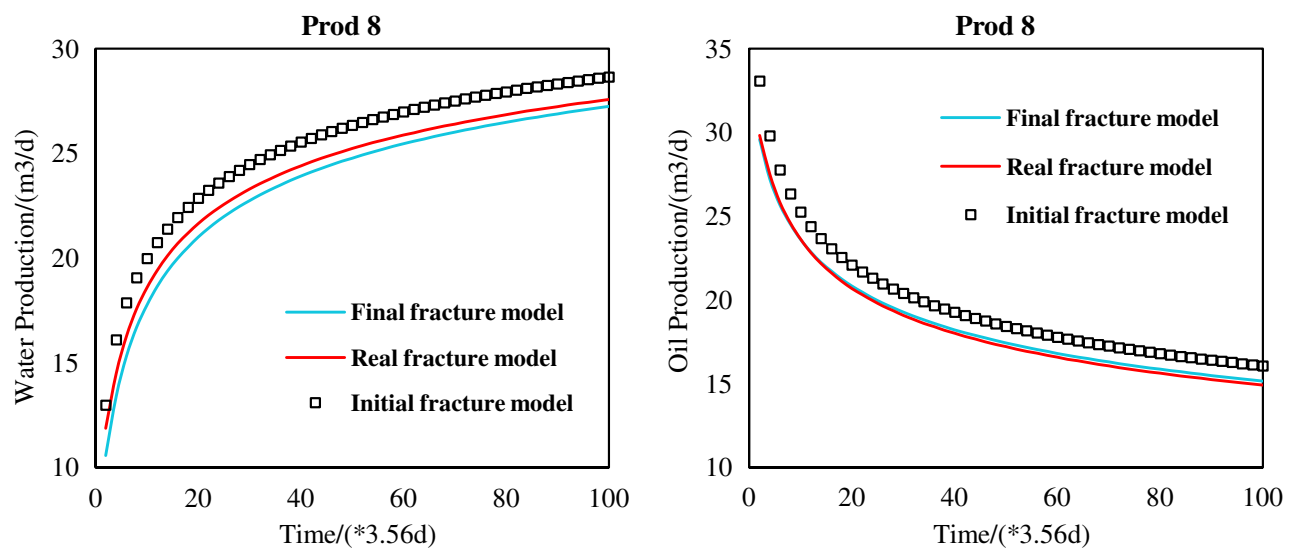

Fig. 12 Production data of Pro8. 

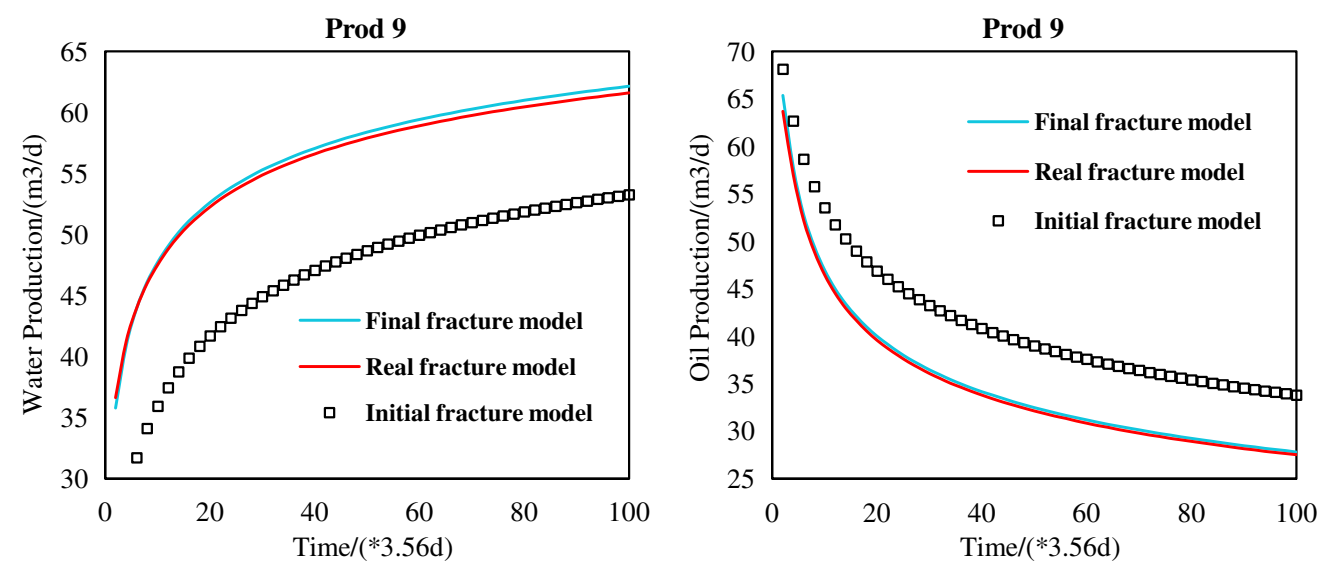

Fig. 13 Production data of Pro9.

Table 5 Parameters Matching Result.

\begin{tabular}{clll}
\hline Number & \multicolumn{1}{c}{ Parameters } & \multicolumn{1}{c}{$\boldsymbol{\alpha}$} & \multicolumn{1}{c}{$\boldsymbol{L}$} \\
\hline \multirow{2}{*}{1} & Real fracture model & 45 & 424 \\
& Final fracture model & 44.70 & 424.10 \\
2 & Real fracture model & 45 & 212 \\
& Final fracture model & 46.05 & 244.33 \\
3 & Real fracture model & 45 & 212 \\
& Final fracture model & 48.11 & 232.25 \\
\hline
\end{tabular}

the practical fracture network parameters and the process is shown in Figs. $18,20$.

The fractures' shape and remaining oil saturation distribution of the final fracture model are approximated to the real fracture model. From Table 6. the parameters of final fractures model are close to the real fractures model and have a great improvement compared with the initial fractures model.

Similarly, the production data curves of several representative wells are shown in Figs. 21]24.

As can be seen from the production curves, the production curves of final fracture model and real fracture model almost overlap and have a greater improved base on the production curves of the initial fracture model. Compared with single fracture model, Pro9 oil production of fracture network is higher. This indicates that fracture network provides larger high permeability region than single fracture.

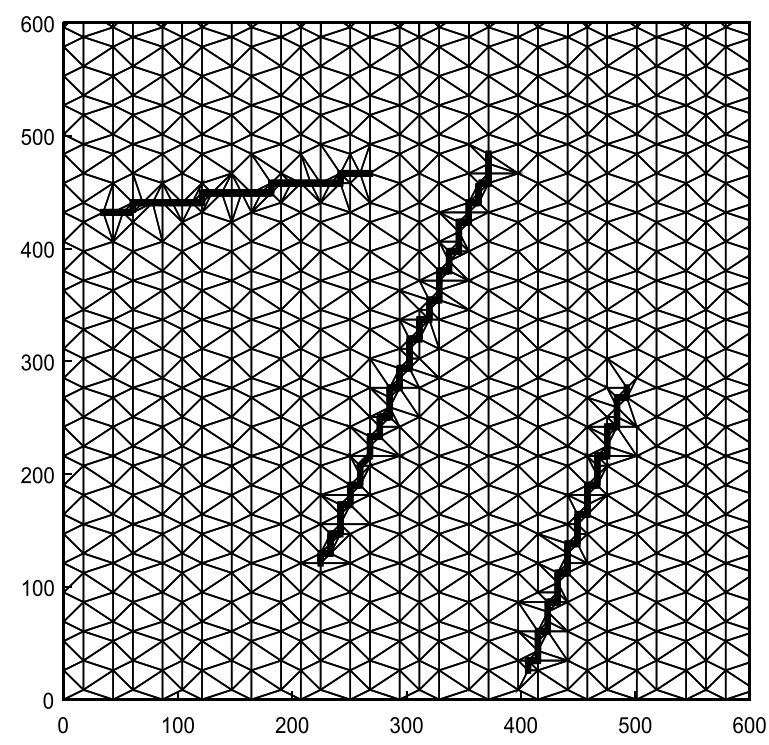

(a) Hydraulic fractures distribution

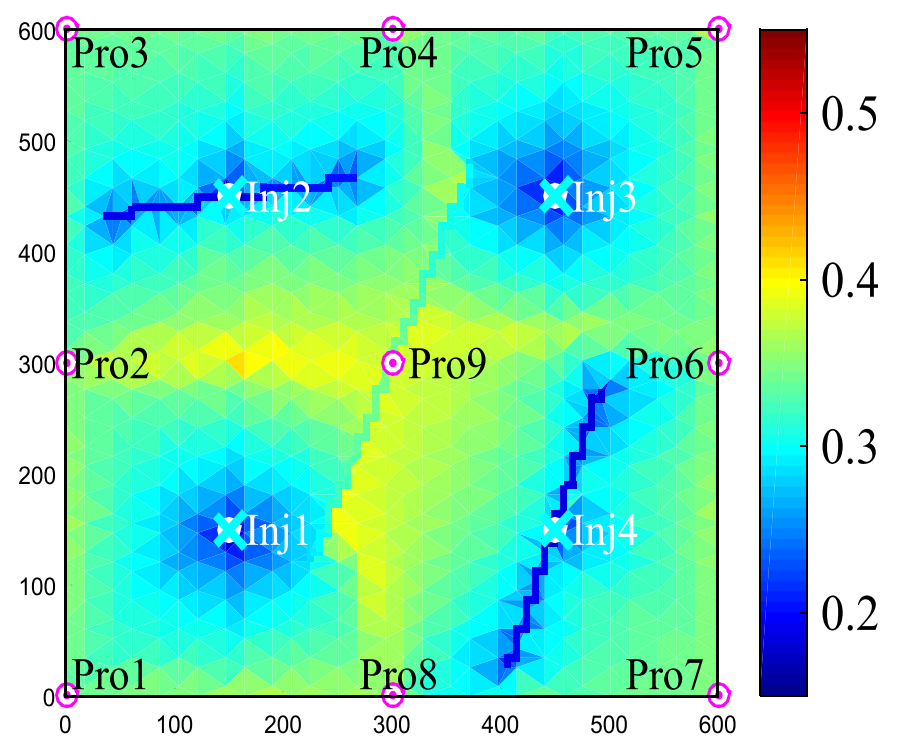

(b) Remaining oil saturation distribution

Fig. 14 Initial fracture model. 


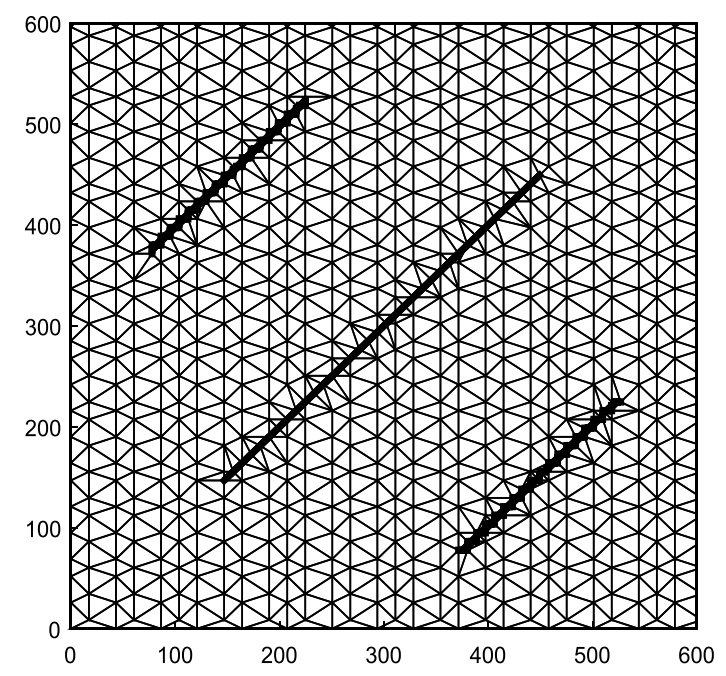

(a) Hydraulic fractures distribution

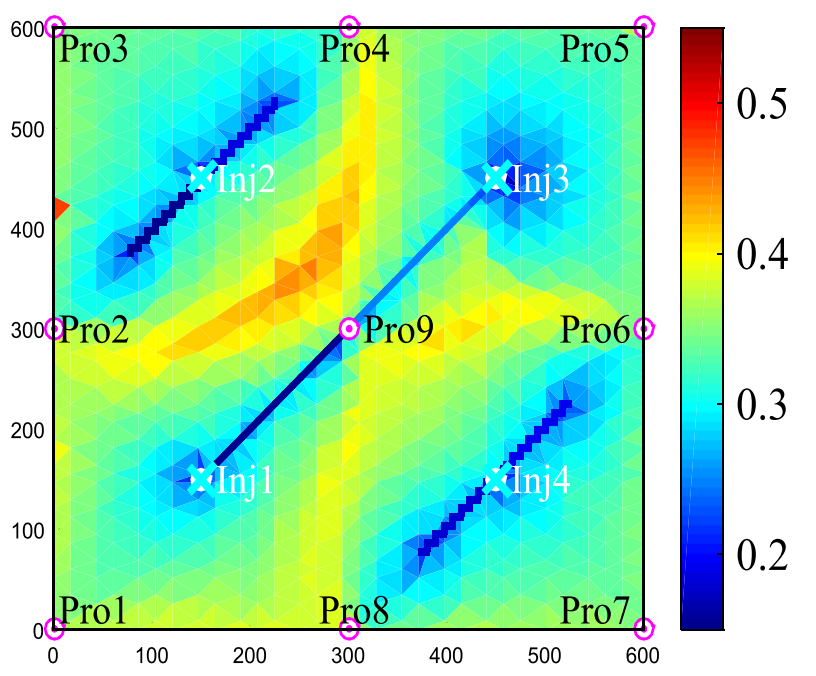

(b) Remaining oil saturation distribution

Fig. 15 Real fracture model.

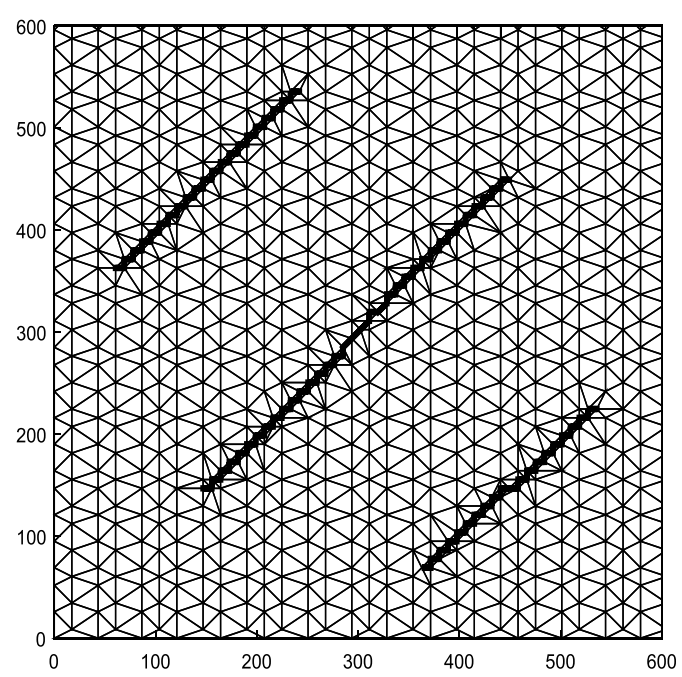

(a) Hydraulic fractures distribution

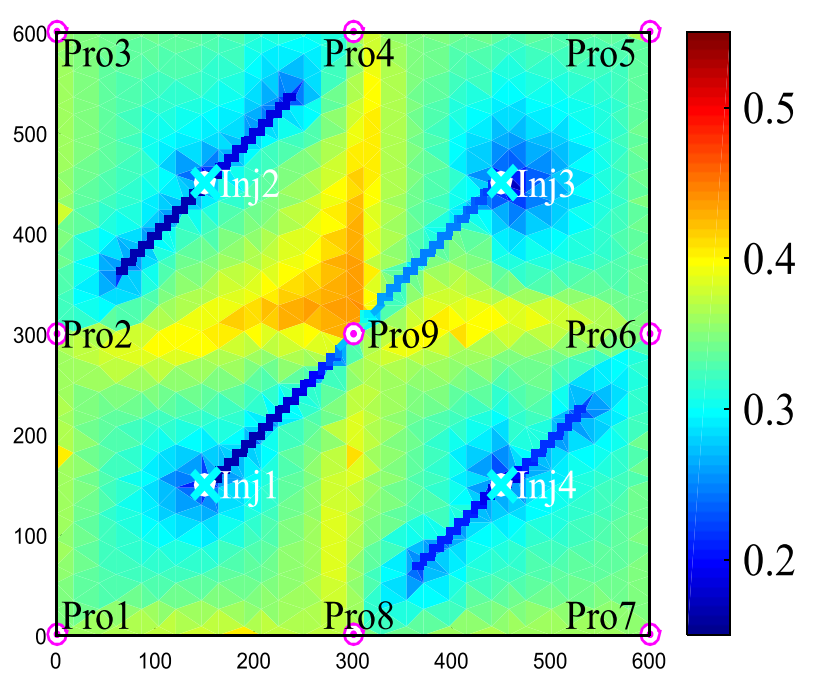

(b) Remaining oil saturation distribution

Fig. 16 Final fracture model.
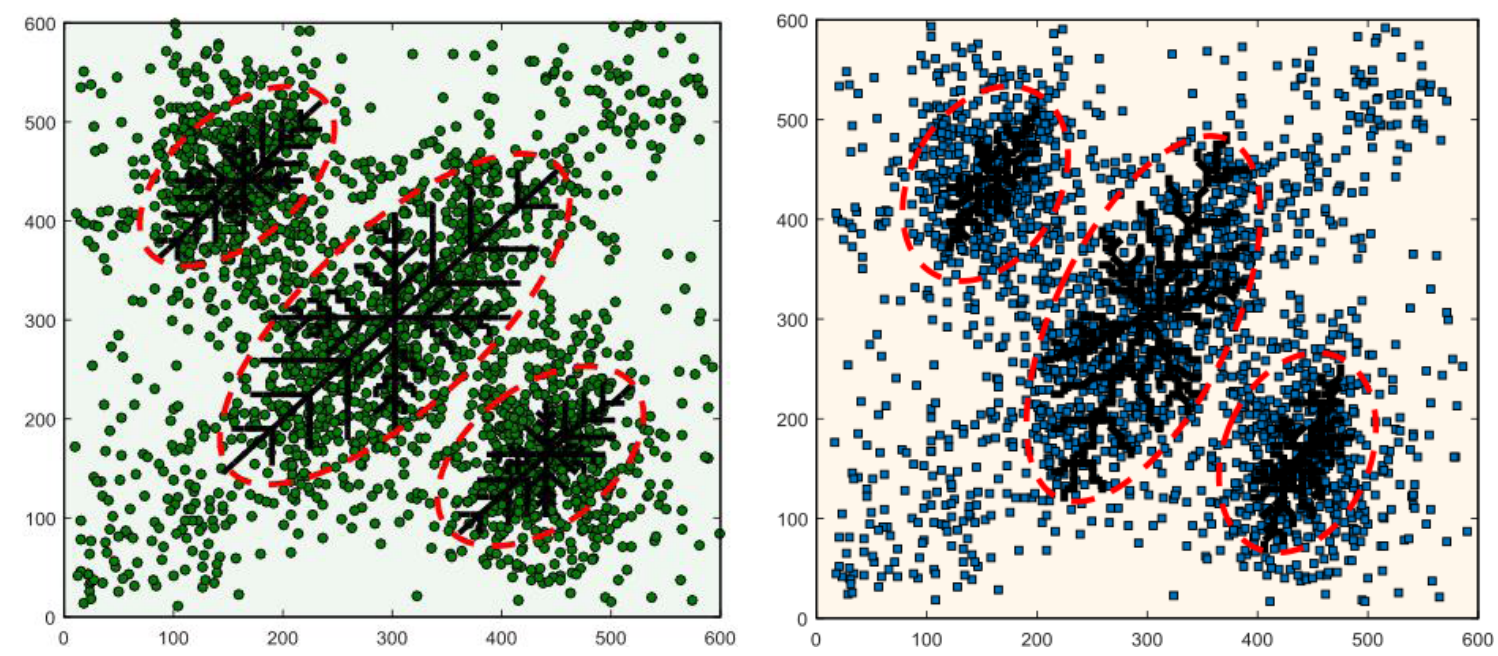

Fig. 17 The distribution of real fracture network and initial fracture network. 


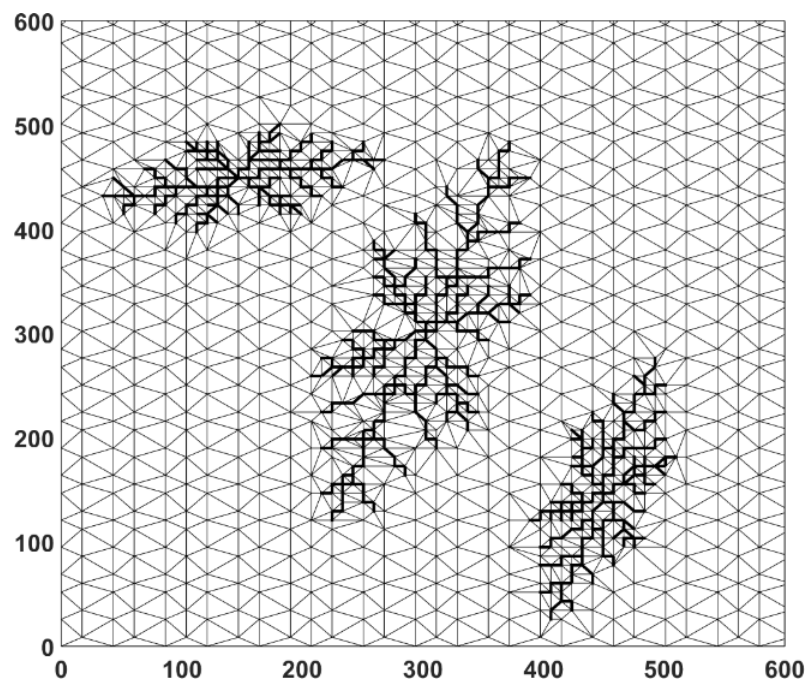

(a) Hydraulic fractures distribution

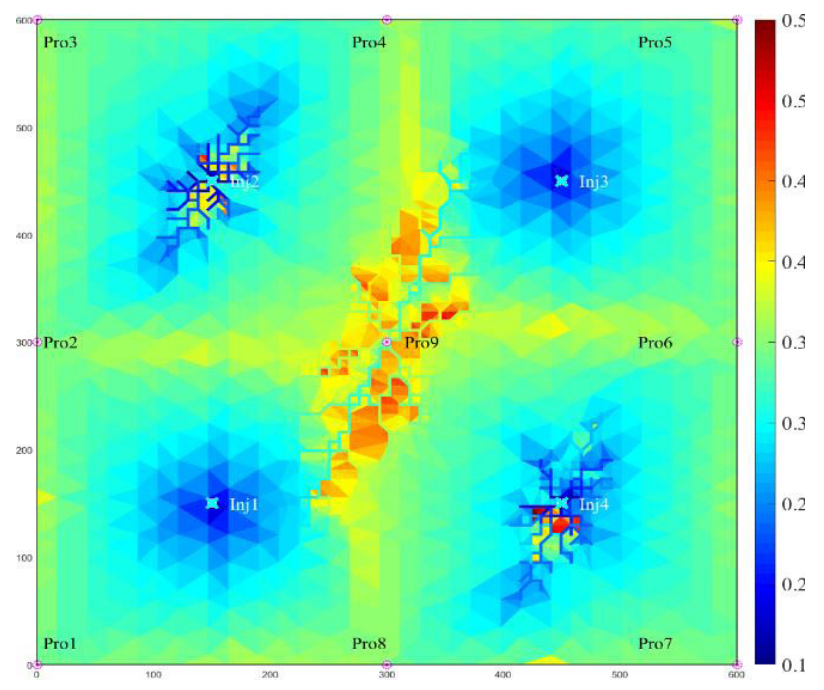

(b) Remaining oil saturation distribution

Fig. 18 The initial fracture network model.

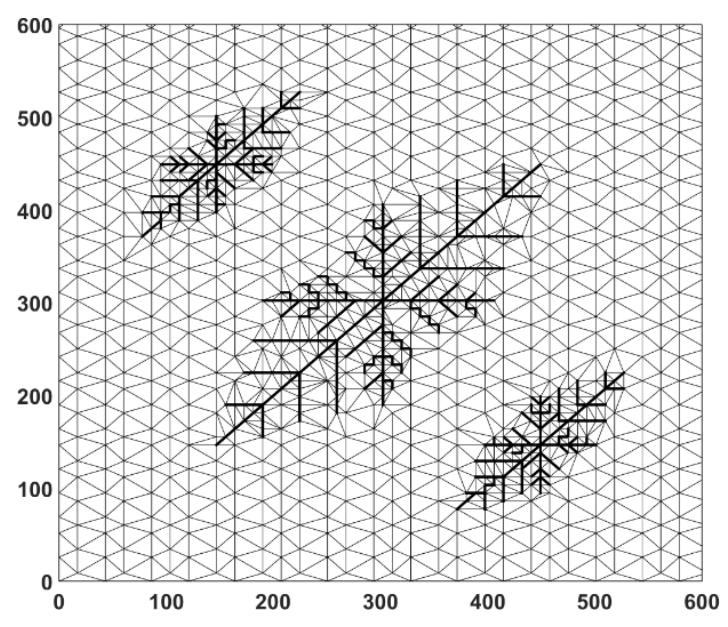

(a) Hydraulic fractures distribution

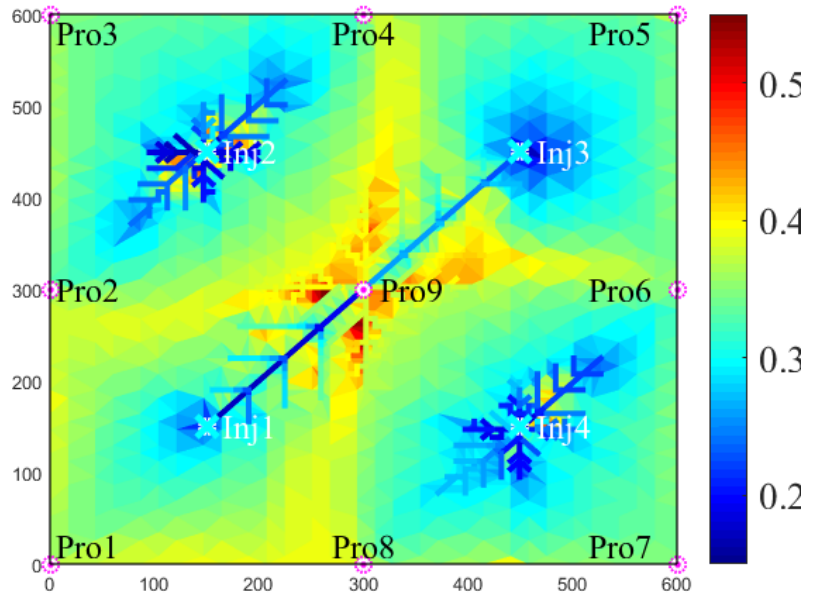

(b) Remaining oil saturation distribution

Fig. 19 The real fracture network model.

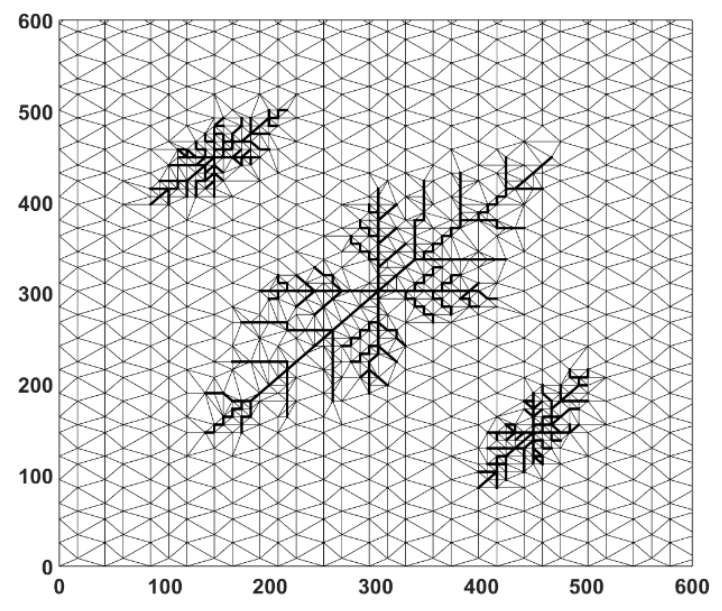

(a) Hydraulic fractures distribution

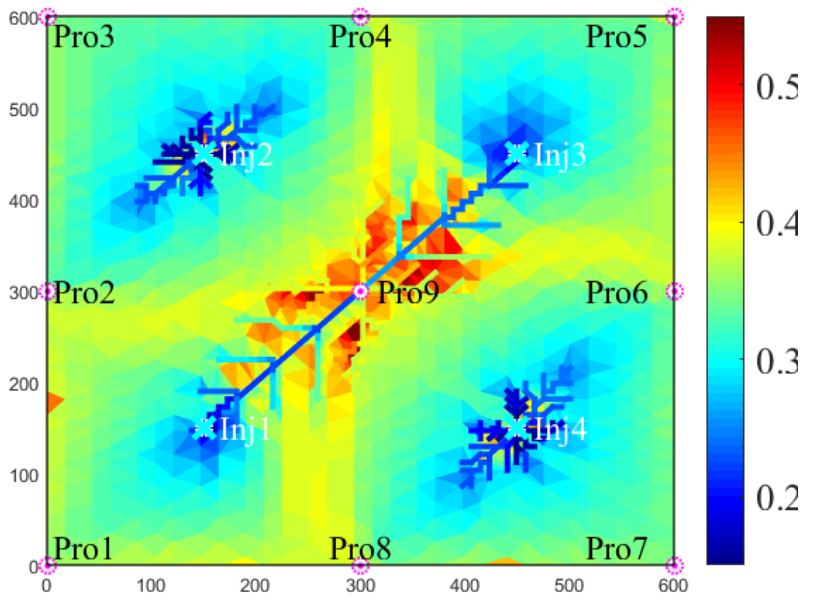

(b) Remaining oil saturation distribution

Fig. 20 The final fracture network model. 
Table 6 Parameters Matching Result.

\begin{tabular}{clll}
\hline $\begin{array}{c}\text { Parameters } \\
\text { Number }\end{array}$ & & $\boldsymbol{\alpha}$ & $\boldsymbol{L}$ \\
\hline \multirow{2}{*}{1} & Initial fracture model & 67.47 & 394.03 \\
& Real fracture model & 45 & 424 \\
& Final fracture model & 43.12 & 448.22 \\
2 & Initial fracture model & 10 & 240 \\
& Real fracture model & 45 & 212 \\
& Final fracture model & 39.00 & 159.28 \\
\multirow{2}{*}{3} & Initial fracture model & 70 & 260 \\
& Real fracture model & 45 & 212 \\
& Final fracture model & 50.91 & 166.29 \\
& & &
\end{tabular}

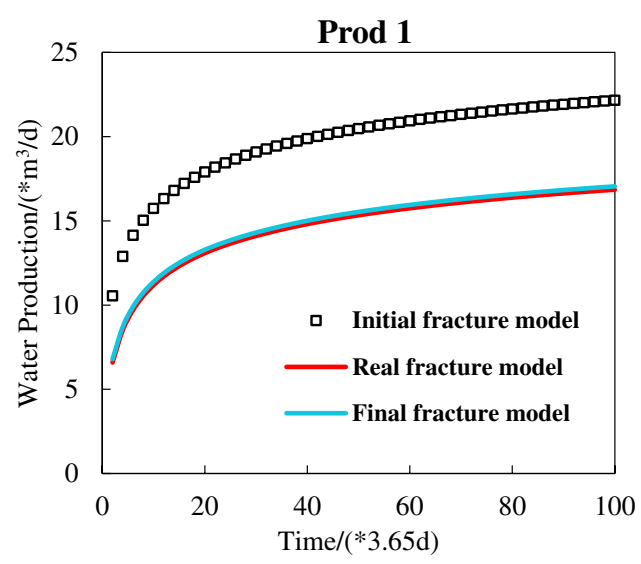

(a) Water production of Pro1

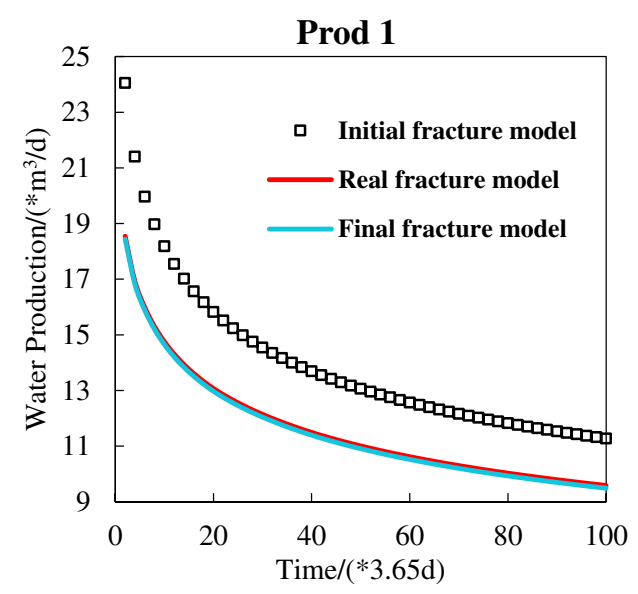

(b) Oil production of Pro1

Fig. 21 Production data of Pro1.

Figure 25] shows the objective function curve.

As shown in Fig. 25] the objective function value at the previous 10 iteration steps decreases fast, the objective function value decreases about $97 \%$. But after eight iteration steps it decreases slower,

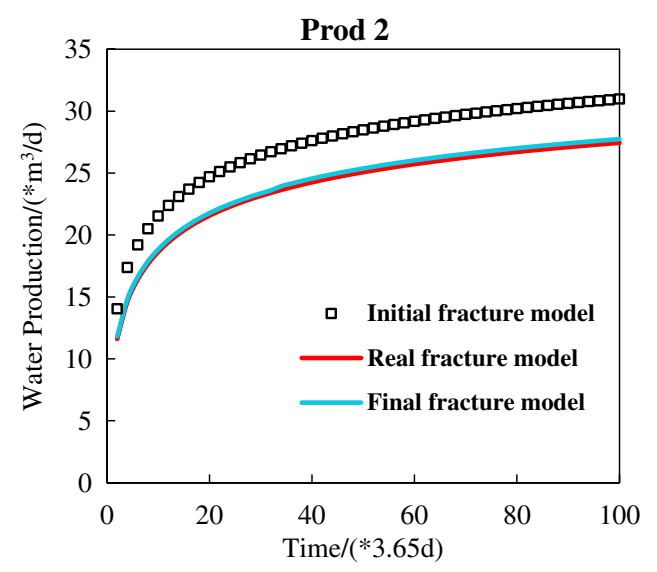

(a) Water production of Pro2

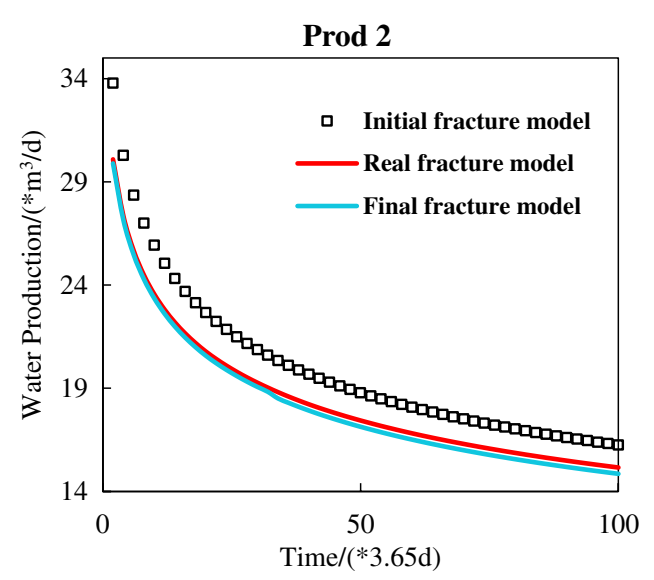

(b) Oil production of Pro2

Fig. 22 Production data of Pro2.

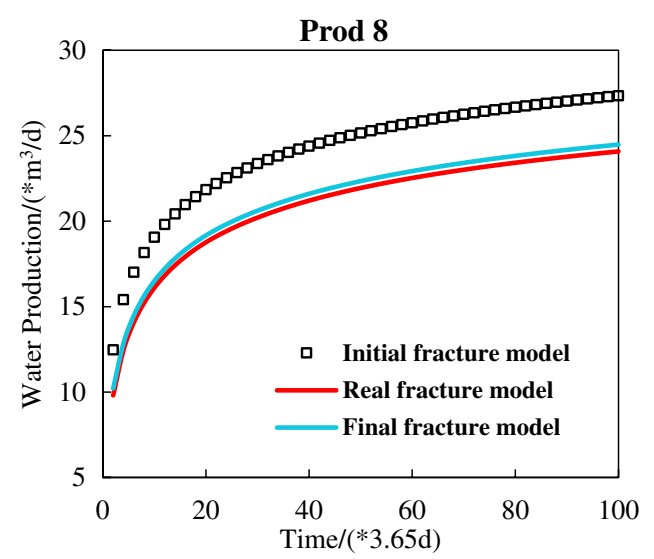

(a) Water production of Pro8

Fig. 23 Production data of Pro8.

and after 75 iteration steps the objective function no longer declines. The reason is that the difference between the initial fracture model and the real fracture model is too large so that it can be optimized quickly at previous time step, but at the 


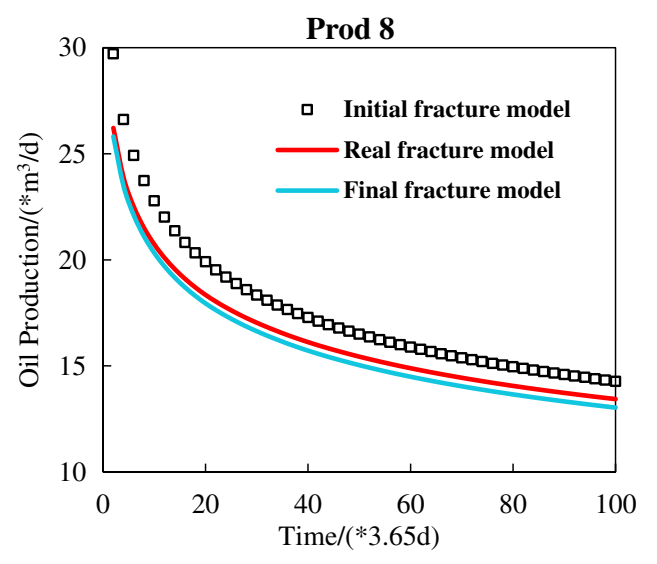

(b) Oil production of Pro8

Fig. 23 (Continued)

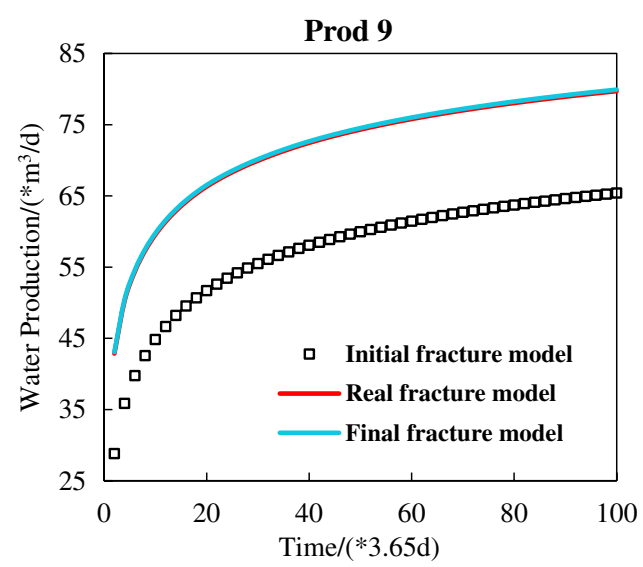

(a) Water production of Pro9

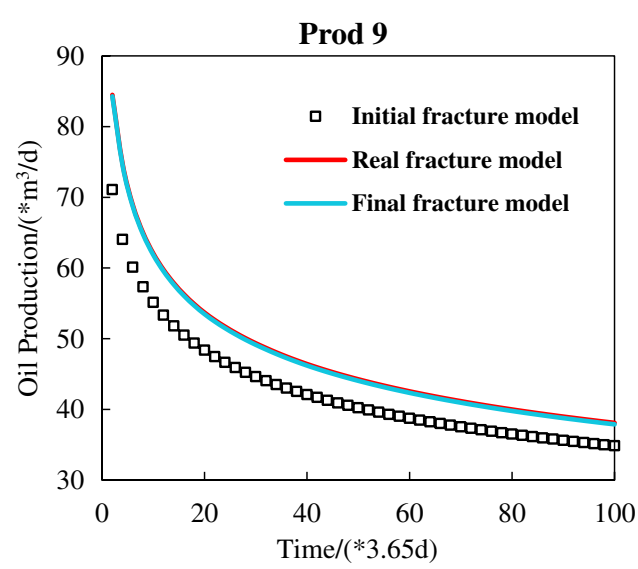

(b) Oil production of Pro9

Fig. 24 Production data of Pro9.

final time step the characteristics of the update fractures have already been closer to the real ones, so the fine-tuning of the amplitude cannot be too much.

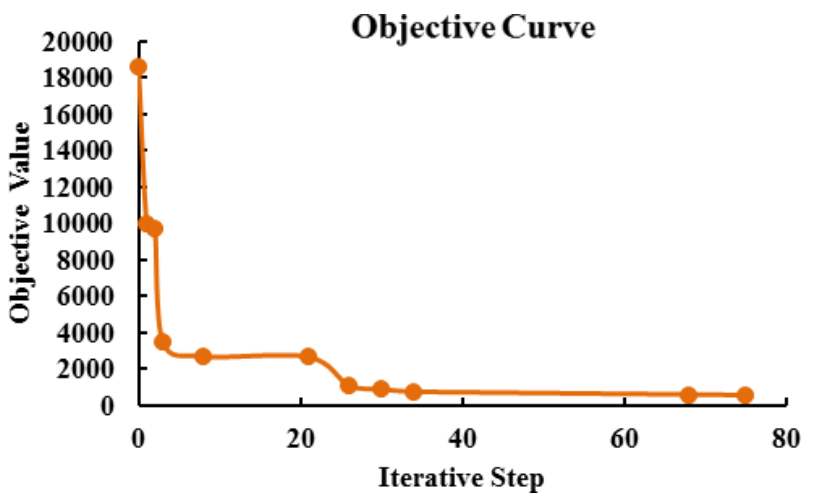

Fig. 25 The objective function value versus the iteration steps.

\section{CONCLUSION}

In this study, we integrated micro-seismic data interpretation with history matching to predict hydraulic fracture parameters. First, we used microseismic source inversion to estimate the fracture shape and its distribution area, predict the static characteristics of fractures. Then we considered the secondary modeling by means of dynamic production data to analyze the dynamic characteristics of hydraulic fracture for describing the fractures accurately.

(1) Based on the shooting ray tracing method establishing the source location model, we used the double difference method to construct the objective function and used the SPSA algorithm for the objective function optimization, achieved rapid and efficient source location.

(2) Analysis of the results proved that the method of this paper is effective. Incorporating microseismic inversion with the dynamic production data analysis can predict the hydraulic fracture more quickly and accurately. Moreover, the process of fracturing also generated many micro-branch fractures, especially the fracture network may greatly increase the inversion difficulty during the production, which needs further study.

\section{ACKNOWLEDGMENTS}

The work is supported by "The National Natural Science Foundation of China" Under Grant 51722406 and 61573018, "The Natural Science Foundation of Shan Dong Province" Under Grant ZR201709210024 and ZR2015EL014, "China Important National Science \& Technology Specific Projects" Under Grant 2016ZX05025001-006, 
the Fundamental Research Funds for the Central Universities" Under Grant 18CX02097A and 17CX05002A.

\section{REFERENCES}

1. J. C. Cai and S. Y. Sun, Fractal analysis of fracture increasing spontaneous imbibition in porous media with gas-saturated, Int. J. Mod. Phys. C 24(8) (2013) 1350056.

2. C. L. Cipolla and C. A. Wright, State-of-the-art in hydraulic fracture diagnostics, in SPE Asia Pacific Oil and Gas Conf. Exhibition (Society of Petroleum Engineers, 2000).

3. A. D. Wood and B. Hazra, Characterization of organic-rich shales for petroleum exploration \& exploitation: A review-Part 3: Applied geomechanics, petrophysics and reservoir modeling, J. Earth Sci. 28(5) (2017) 779-803.

4. W. Q. Song, Y. K. Gao and H. W. Zhu, The differential evolution inversion method based on Bayesian theory for micro-seismic data, Diqiu Wuli Xuebao 56(4) (2013) 1331-1339.

5. Y. Tan, C. He and H. Zhang, Microseismic velocity model inversion based on moveouts of first arrivals, Shiyou Diqiu Wuli Kantan (Oil Geophys. Prospect.) 50(1) (2015) 54-60.

6. J. Vidale, Finite-difference calculation of travel times, Bull. Seismol. Soc. Amer. 78(6) (1988) 20622076.

7. J. V. Trier and W. W. Symes, Upwind finitedifference calculation of travel-times, Geophysics 56(6) (2012) 812-821.

8. P. Sava and S. Fomel, Huygens wavefront tracing: A robust alternative to ray tracing, Seg. Techn. Program Expand. Abstr. 17(1) (1998) 1961.

9. T. J. Moser, Shortest path calculation of seismic rays, Geophysics 56(1) (2012) 59-67.

10. L. J. Huang, The wave-front ray tracing method for image reconstruction, Chin. J. Geophys. 2 (1992) 013.

11. E. G. Gao and G. M. Xu, A new kind of step by step iterative ray-tracing method, Chin. J. Geophys. 39 (1996) 302-308.

12. Y. Zhao et al., Total iterative ray tracing in 3-d layered structure, Computing Techniques for giophysical and Geochemical Exploration (2001).

13. T. N. Bishop et al., Tomographic determination of velocity and depth in laterally varying media, Geophysics 50(6) (1985) 903-923.

14. N. D. Bregman, R. C. Bailey and C. H. Chapman, Crosshole seismic tomography, Geophysics 54(2) (1989) 200-215.
15. L. Geiger, Probability method for the determination of earthquake epicenters from the arrival time only, Bull. St. Louis Univ. 8(1) (1912) 56-71.

16. F. Waldhauser and W. L. Ellsworth, A doubledifference earthquake location algorithm: Method and application to the northern Hayward fault, California, Bull. Seismol. Soc. Amer. 90(6) (2000) 13531368.

17. O. V. Poliannikov et al., Interferometric hydrofracture microseism localization using neighboring fracture, Geophysics 76(6) (2011) WC27-WC36.

18. W. Q. Song and X. D. Yang, A joint inversion combining the grid-search algorithm and the genetic algorithm under solution-domain constraints for microseismic events, Shiyou Diqiu Wuli Kantan (Oil Geophys. Prospect.) 46(2) (2011) 259-266.

19. D. Pei et al., Velocity calibration for microseismic monitoring: A very fast simulated annealing (VFSA) approach for joint-objective optimization, Geophysics 74(6) (2009) WCB47-WCB55.

20. K. Deep, A. Yadav and S. Kumar, Improving local and regional earthquake locations using an advance inversion technique: Particle swarm optimization, World J. Model. Simul. 8(2) (2012) 135-141.

21. D. Skoko and Y. Sato, Optimum distribution of seismic observation points. III, Bull. Earthquake Res. Inst. 44(1) (1966) 13-22.

22. A. Kijko, An algorithm for the optimum distribution of a regional seismic network-I, Pure Appl. Geophys. 115(4) (1977) 999-1009.

23. W. Song et al., Microseismic source vector inversion, Geophys. Prospect. Petrol. 53(6) (2014) 692698.

24. J. E. Gale et al., Collection, analysis, and integration of discrete fracture data from the monterey formation for fractured reservoir simulations, in SPE Annual Technical Conf. and Exhibition (Society of Petroleum Engineers, 1991).

25. R. A. Schaefer, J. E. Gale and A. Herbert, 3-D discrete fracture flow simulations using Monterey formation fracture data, in SPE Reservoir Simulation Symp. (Society of Petroleum Engineers, 1995).

26. M. I. Kamouei and T. Yildiz, Transient flow in discretely fractured porous media, SPE J. 14(2) (2009) 362-373.

27. T. H. Kim and D. S. Schechter, Estimation of fracture porosity of naturally fractured reservoirs with no matrix porosity using fractal discrete fracture networks, SPE Reserv. Eval. Eng. 12(2) (2009) 232242.

28. A. Moinfar et al., Comparison of discrete-fracture and dual-permeability models for multiphase flow in naturally fractured reservoirs, in SPE Reservoir 
Simulation Symp. (Society of Petroleum Engineers, 2011).

29. T. Doe et al., Evaluating the effect of natural fractures on production from hydraulically fractured wells using discrete fracture network models, in Unconventional Resources Technology Conf. (Society of Petroleum Engineers, 2013).

30. K. Lie et al., Open-source MATLAB implementation of consistent discretisations on complex grids, Comput. Geosci. 16(2) (2012) 297-322.

31. T. H. Sandve, I. Berre and J. M. Nordbotten, An efficient multi-point flux approximation method for discrete fracture-matrix simulations, J. Comput. Phys. 231(9) (2012) 3784-3800.

32. C. J. Spall, A stochastic approximation technique for generating maximum likelihood parameter estimates, in American Control Conf. (IEEE, 1987).

33. C. J. Spall, Multivariate stochastic approximation using a simultaneous perturbation gradient approximation, IEEE Trans. Autom. Control 37(3) (1992) $332-341$.

34. J. C. Cai et al., An introduction to flow and transport in fractal models of porous media: Part II, Fractals 23(1) (2015) 1402001.

35. W. Wei et al., An electrical conductivity model for fractal porous media, Geophys. Res. Lett. $\mathbf{4 2 ( 1 2 )}$ (2015) 4833-4840.

36. P. M. Adler and J. F. Thovert, Fractal porous media, Transp. Porous Media 13(1) (1993) 41-78.

37. X. H. Tan et al., A simulation method for permeability of porous media based on multiple fractal model, Int. J. Eng. Sci. 95 (2015) 76-84.

38. W. D. Wang et al., Analysis of the complex fracture flow in multiple fractured horizontal wells with the fractal tree-like network models, Fractals 23(2) (2015) 1550014.

39. V. V. Silberschmidt and V. G. Silberschmidt, Fractal models in rock fracture analysis, Terra Nova $\mathbf{2}(5)$ (1990) 483-488.

40. X. H. Tan et al., A model for transient flow in porous media embedded with randomly distributed tree-shaped fractal networks, Int. J. Mod. Phys. B 29(19) (2015) 1550135.

41. Z. Q. Huang, B. Gao and Y. Y. Wang, Two-phase flow simulation of discrete fracture model using a novel mimetic finite difference method, J. China Univ. Petrol. 38(6) (2014) 97-105.

42. Z. X. Sun et al., Dynamic analysis of horizontal wells with complex fractures based on a discrete-fracture model, J. China Univ. Petrol. 38(2) (2014) 109-115.

43. M. Shakiba and K. Sepehrnoori, Using embedded discrete fracture model (EDFM) and microseismic monitoring data to characterize the complex hydraulic fracture networks, in SPE Annual Technical Conf. and Exhibition (Society of Petroleum Engineers, 2015).

44. J. E. Aarnes, T. Gimse and K. A. Lie, An introduction to the numerics of flow in porous media using Matlab, in Geometrical Modelling Numerical Simulation and Optimization: Industrial Mathematics at SINTEF (Springer, 2007), pp. 265-306.

45. J. C. Cai et al., Fractal characterization of dynamic fracture network extension in porous media, Fractals 25(2) (2017) 1750023.

46. B. R. Meyer and L. W. Bazan, A discrete fracture network model for hydraulically induced fractures-theory, parametric and case studies, in SPE Hydraulic Fracturing Technol. Conf. (Society of Petroleum Engineers, 2011).

47. B. Meyer et al., Optimization of multiple transverse hydraulic fractures in horizontal wellbores, in SPE Unconventional Gas Conf. (Society of Petroleum Engineers, 2010).

48. P. Prusinkiewicz and A. Lindenmayer, The algorithmic Beauty of Plants (Springer Science \& Business Media, 2012).

49. T. K. Guo, S. C. Zhang and H. K. Ge, A new method for evaluating ability of forming fracture network in shale reservoir, Rock Soil Mech. 34(4) (2013) 947954.

50. B. Hahn and A. K. R. Oldham, A model-free $\mathrm{ON}-\mathrm{OFF}$ iterative adaptive controller based on stochastic approximation, IEEE Trans. Control Syst. Technol. 20(1) (2012) 196-204.

51. Q. Wang and J. C. Spall, Discrete simultaneous perturbation stochastic approximation on loss function with noisy measurements, Amer. Control Conf. $(A C C)$ (IEEE, 2011). 